\title{
El acaparamiento del subsuelo: conflictos y justicia en Guanajuato en las últimas décadas del siglo XVIII y las primeras del siglo XIX
}

Underground Hoarding: Conflicts and Justice in Guanajuato in the late Eighteenth and Early Nineteenth Centuries

Accaparement du sous-sol: conflits et justice à Guanajuato dans la dernière décennie du XVIIIe siècle et les premières du XIXe siècle

\section{Margarita Villalba Bustamante}

\section{OpenEdition}

\section{Journals}

Edición electrónica

URL: http://journals.openedition.org/rhj/1226

DOI: 10.4000/rhj. 1226

ISSN: 0719-4153

Editor

ACTO Editores Ltda

Referencia electrónica

Margarita Villalba Bustamante, « El acaparamiento del subsuelo: conflictos y justicia en Guanajuato en las últimas décadas del siglo XVIII y las primeras del siglo XIX », Revista Historia y Justicia [En línea], 9 | 2017, Publicado el 07 diciembre 2017, consultado el 03 mayo 2019. URL : http:// journals.openedition.org/rhj/1226; DOI : 10.4000/rhj.1226 


\title{
EL ACAPARAMIENTO DEL SUBSUELO: CONFLICTOS Y JUSTICIA EN GUANAJUATO EN LAS ÚLTIMAS DÉCADAS DEL SIGLO XVIII Y LAS PRIMERAS DEL SIGLO XIX
}

\author{
Margarita VILLALBA BUSTAMANTE (*)
}

\begin{abstract}
Se analizan varios conflictos mineros en los que estuvieron involucrados grandes, medianos y pequeños empresarios guanajuatenses durante las últimas décadas del siglo XVIII y principios del XIX. Se pretende explicar el proceso de acaparamiento del subsuelo novohispano inherente a la expansión de las minas más ricas y productivas, considerando las circunstancias económicas y sociopolíticas que lo determinaron. Tres aspectos fueron decisivos en ese proceso: la desigual distribución de la propiedad minera; los vínculos entre los jueces y las partes litigantes; y la justicia privativa de los tribunales de minería. Todos comprometieron tanto la administración de justicia como el desarrollo de los distintos sectores de la industria minera.
\end{abstract}

Palabras Clave: conflictos mineros, justicia, jueces de minas, Guanajuato, siglos XVIII y XIX

Before Underground Hoarding: Conflicts and Justice in Guanajuato in the late Eighteenth and Early Nineteenth Centuries 1783

This paper describes how large, medium, and small businesses in Guanajuato were involved in several mining conflicts during the last decades of the eighteenth and the beginning of the nineteenth century. By doing so, it seeks to explain the process of "subsoil hoarding" in New Spain.

This process was inherent to the expansion of the richest and most productive mines, considering its economic and socio-political circumstances.

Three crucial aspects were decisive in explaining this outcome: the unequal distribution of mining property, the links between judges and litigants, and the exclusive jurisdiction of mining courts. All these aspects

compromised the administration of justice and the development of different sectors of the mining industry.

Keywords: Mining conflicts, justice, mining judges, Guanajuato, 18th and 19th centuries
Accaparement du sous-sol: conflits et justice à Guanajuato dans la dernière décennie du XVIIIe siècle et les premières du XIXe siècle

Cet article analyse plusieurs conflits miniers dans lesquels de grands, moyens et petits entrepreneurs de Guanajuato furent impliqués, au cours des dernières décennies du XVIIII siècle et les premières du siècle suivant.

Ce faisait, nous tentons d'expliquer le processus d'accaparement du sous-sol en Nouvelle Espagne, inhérent à l'expansion des mines les plus riches et les plus productives, en tenant compte des circonstances économiques et socio-politiques qui déterminèrent ce processus. Trois aspects furent décisifs: la distribution inégale de la propriété des mines; les liens entre les juges et les parties aux procès; la justice propre aux tribunaux des mines. Tous mettaient en cause aussi bien l'administration de la justice que le développement de différents secteurs de l'industrie minière.

Mots clé: conflits miniers, justice, juges des mines, Guanajuato, XVIIIe-XIXe siècle

Recibido: 24 de julio de 2017 / Aceptado: 22 de octubre de 2017

(*) Maestra en Historia, Facultad de Filosofía y Letras, Universidad Nacional Autónoma de México. Investigadora independiente, México. mvillalba58@hotmail.com. 


\title{
El acaparamiento del subsuelo: conflictos y justicia en Guanajuato en las últimas décadas del siglo XVIII y las primeras del siglo XIX
}

\author{
Margarita VILLALBA BUSTAMANTE
}

\section{Introducción}

La historiografía sobre la minería novohispana de las últimas décadas del siglo XVIII y las primeras del siglo XIX no ha abordado, de manera específica, el tema del acaparamiento del subsuelo y la propiedad minera, ni los conflictos que éste suscitó entre los empresarios mineros. No obstante, algunos estudiosos enfatizan que este período se caracterizó por las frecuentes disputas entre ellos.

Frédérique Langue muestra que, durante la primera mitad del siglo XVIII, Zacatecas fue escenario de numerosos pleitos entre los grandes mineros, y a partir de ellos descubre la existencia de verdaderos grupos locales de presión, de alianzas y fidelidades en beneficio de los más influyentes. Para ello, Langue contó con diversos procesos judiciales sobre el desagüe común de varias minas zacatecanas en posesión de empresarios, cuyos irreconciliables intereses causaron su ruina. Otro aspecto puesto de relieve por esta autora es la superposición de la jurisdicción de las autoridades locales -los alcaldes mayores y la diputación de minería-, la Audiencia de Guadalajara y el virrey. Asimismo, subrayó la incidencia de las lagunas en las Ordenanzas de minería de 1783, respecto del "acaparamiento de minas" en manos de los mineros más ricos, aunque no indica en qué se tradujo eso ${ }^{1}$.

\footnotetext{
${ }^{1}$ Frédérique Langue muestra que los grandes mineros aprovecharon las lagunas en la legislación para defender sus intereses así como que sus frecuentes conflictos paralizaron varias minas, enfatizando que su solución dependió más de la visita de los oidores que de los tribunales de primera instancia, cuya función se vio ensombrecida por su impericia y complicidad. A esto se sumó el interés de la Corona española en rehabilitar las minas de Zacatecas para promover el aumento de la plata y el dinero que ingresaba en la Real hacienda. Langue observa que los conflictos mineros en Sombrerete presentaron características similares: la intervención de las autoridades locales a favor de uno de los contrincantes; la confrontación entre las autoridades locales y las virreinales y, la tendencia de las últimas
} 


\section{Revista Historia y Justicia}

Por su parte, David Brading prueba que, entre las causas que impidieron el desarrollo de la minería guanajuatense en esa misma época, se encontraban las frecuentes quiebras protagonizadas por los principales mineros, así como la "excesiva división de los derechos" de la propiedad minera. Para justificar esto, este investigador analiza los procesos judiciales en los que se involucraron los dueños de las minas de Rayas, Mellado y Cata, debilitados por sus disputas en el seno de su propia empresa a causa de su posesión y por la falta de capital para rehabilitarlas. Así, aunque Brading diferencia las circunstancias de la prosperidad que experimentó la minería después de mediados del siglo, no considera el acaparamiento del subsuelo como una de sus condiciones ${ }^{2}$.

Este trabajo constituye, pues, un primer acercamiento para explicar el acaparamiento del subsuelo como una condición del proceso de expansión subterránea de las minas más ricas y productivas de Guanajuato, durante las últimas décadas del siglo XVIII y las primeras del siglo XIX. Ello, en un contexto que se caracterizó tanto por la gran producción de metales preciosos como por la formación y consolidación de diferentes empresarios mineros, los cuales acumularon en el seno de sus minas varias pertenencias o terrenos ubicados en la veta madre. Esto permitirá mostrar, en parte, las condiciones económicas y sociopolíticas que favorecieron ese acaparamiento en dos ámbitos: el de los empresarios mineros, en tanto que concesionarios de fundos metálicos con una cierta trayectoria, y el de las instituciones a cargo de resolver los juicios de propiedad minera según las Ordenanzas de Minería de 1783. Así, pretendo revelar las peculiaridades y contradicciones de las relaciones prevalecientes entre los empresarios mineros que se disputaron la posesión de minas o alguna de sus pertenencias y, entre los empresarios y los tres juzgados de minas: la Diputación de Minería, el Juzgado de Alzadas y el Real Tribunal de Minería.

Para abordar el fin expuesto, esta investigación empieza asumiendo dos supuestos. Dada la especificidad de la figura dominante de los grandes empresarios mineros en la industria minera local y virreinal, ellos fueron, sin duda, los mayores acaparadores del subsuelo. Nada podía impedirlo. Ni siquiera las recién creadas instituciones competentes para administrar una "justicia privativa", "breve y sumaria", en los asuntos de minas. No obstante, no pudieron evitar que algunos medianos y pequeños mineros pretendieran disfrutar de la riqueza mineral de la veta madre de Guanajuato. En particular, en el tramo donde se localizaban las minas de Valenciana, Nuestra Señora de Guadalupe de Tepeyac, Señor de San José de Quebradilla y Encarnación del Divino Verbo y otras más. Todas ellas eran colindantes, pero estaban en manos de empresarios con distinto perfil, cuyas empresas, con

a reservarse la jurisdicción de los asuntos de minas, entre otras. Langue, Frédérique, Mines, terres et société à Zacatecas (Mexique) de la fin du XVIIe siècle à l'indépendance, Université de la Sorbonne, París, 1992, p. 94.

2 Brading, David, Mineros y comerciantes en el México Borbónico, (1763-1810), Fondo de Cultura Económica, México, 1985, p. 351. 
dimensiones y estructuras muy disímiles, no tuvieron el mismo potencial para expandirse. No obstante, los empresarios menos favorecidos en el goce de aquella riqueza, se enfrentaron entre sí o contra los grandes mineros, y acudieron a las instancias de ley para defender su derecho a obtener la concesión de minas abandonadas, o situadas en terrenos vírgenes aledaños, para así extender las obras subterráneas de las minas que ya poseían.

Considerando la desigual posición de los empresarios en la industria local, así como el interés que representaban en términos de potencial productivo, era inevitable que la administración de justicia que podían desplegar los tribunales que eran presididos por mineros, se viera comprometida, debido a la influencia determinante de los grandes empresarios. Es conocido que ellos controlaban las instituciones político-administrativas locales, principalmente las diputaciones de minería y el ayuntamiento donde ocupaban distintos cargos. Además, eran miembros, o tenían estrechos vínculos con los miembros de las instituciones virreinales, incluyendo el Tribunal General de Minería. Todo lo anterior pudo determinar un comportamiento errático en las instituciones de justicia, que incidió en el acaparamiento del subsuelo en manos de quienes fueron sus mayores beneficiados.

Entre las fuentes que sustentan este trabajo se encuentran diversos procesos judiciales y denuncios, concernientes a las disputas entre los concesionarios de las minas mencionadas más arriba, así como múltiples documentos relativos a sus trayectorias como empresarios y funcionarios de instituciones públicas, locales y virreinales.

\section{Telón de fondo de los conflictos mineros: el crecimiento de la producción metalífera y la expansión de las minas}

Los conflictos mineros que aquí se abordan tuvieron como telón de fondo la implementación de la nueva política económica impulsada por los borbones a mediados del siglo XVIII, y específicamente, el proyecto modernizador de la industria minera en los reinos de la monarquía española, cuyo objetivo principal era promover el aumento general de la producción de metales preciosos. Este proyecto implicó medidas fiscales. Entre ellas: la reducción del precio de ciertos insumos que eran monopolio de la corona; la elaboración de las Ordenanzas de minería de 1783; la creación de los tres tribunales con jurisdicción privativa para los asuntos de minería -las Diputaciones Territoriales, el Juzgado de Alzadas y el Real Tribunal General de Minería-, a fin de erradicar dos grandes problemas vinculados con la ineficacia de la administración de justicia. Esto es, por un lado, la distracción de recursos para la inversión minera, y por otro lado, la pérdida de ingresos para el Real Erario en el ramo de impuestos al oro y la plata, a causa de los largos y costosos juicios. Asimismo, se crearon el Banco de Avío y el Colegio de Minería, con los propósitos de abatir la insuficiencia de capital destinado a la inversión minera y profesionalizar el trabajo en las minas y haciendas de beneficio, respectivamente. 
La gran producción de oro y plata que se extraía de las minas de Guanajuato a mediados del siglo XVIII atrajo la atención de propios y extraños, incluyendo las autoridades virreinales y viajeros extranjeros, como Alejandro Von Humboldt. Este distrito minero destacó por su papel decisivo en la producción total de metales de Nueva España, desde 1770 y hasta principios del siglo XIX. Sus vetas excedían "en riqueza a cuantas se ha descubierto en las demás partes del mundo"3. Según Humboldt, los 2.5 millones de marcos de plata que salían anualmente de México hacia Europa y Asia provenían no sólo de un reducido número de minas, sino que la mitad de esta suma la proporcionaban Guanajuato, Zacatecas y Catorce. Pero sólo la veta de Guanajuato daba "casi la cuarta parte de toda la plata mexicana y la sexta parte del producto de toda América", lo que la hacía una de las más importantes de Nueva España, gracias en gran parte a la Valenciana, que producía treinta mil marcos de plata por mes $^{4}$. Los historiadores David Brading, Cuauhtémoc Velasco Ávila y Pierre Vilar remarcan, en términos similares, que Guanajuato fue el principal productor de plata en el mundo y que su rendimiento anual, de más de cinco millones de pesos, correspondía a la sexta parte de todos los metales preciosos extraídos en América. La minería guanajuatense era la más consistente y regular de los distritos mineros novohispanos, gracias a que la región, en su conjunto, produjo entre una quinta y cuarta parte de la plata mexicana a fines del siglo XVIII ${ }^{5}$.

\footnotetext{
${ }^{3}$ Humboldt, Alejandro, Ensayo político sobre el reino de la Nueva España, Ed. Porrúa, México, 1991, p. 331-340.

${ }^{4}$ Véanse las obras siguientes: Antúnez Echegaray, Francisco, Monografia bistórica y minera sobre el distrito minero de Guanajuato, Consejo de Recursos No Renovables, México, 1964; Bargalló, Modesto, La minería en la América Española durante la época colonial, Fondo de Cultura Económica, México, 1955; Brading, David, Mineros y comerciantes en el México Borbónico (1763-1810), Fondo de Cultura Económica, México, 1985; Hausberger, Bernd, La Nueva España y sus metales preciosos. La industria minera colonial a partir de los libros de cargo y data de 1761-1767, Iberoamericana, Ververt, Berlín, 1997; Humboldt, Alejandro, Ensayo politico sobre el reino de la Nueva España, México Ed. Porrúa, México, 1991; López Miramontes, Álvaro \& Urrutia Stebelski, Cristina, Las minas de Nueva España en 1774, Secretaría de Educación Pública / Instituto Nacional de Antropología e Historia, México, 1980; Monroy, Pedro, Las minas de Guanajuato. Memoria bistórico descriptiva de este distrito minero, Secretaría de Fomento, México, 1888; Ramírez, Santiago, Noticia histórica de la riqueza minera de México y su actual estado de explotación, Secretaria de Fomento, México, 1884; Velasco Ávila, Cuauhtémoc, Estado y Minería en México (1767-1910), Fondo de Cultura Económica / SEMIP, México, 1988; Vilar, Pierre, Oro y moneda en la bistoria (1450-1920), Ediciones Ariel, Barcelona, 1979. Como estudios regionales se recomienda ver las obras de Alatriste, Oscar, Desarrollo de la industria y la comunidad minera de Hidalgo del Parral durante la segunda mitad del siglo XVIII (1765-1810), Universidad Nacional Autónoma de México, México, 1983; Bakewell, P. J., Minería y sociedad en el México colonial, Zacatecas (1546-1700), Fondo de Cultura Económica, México, 1984; Hadley, Phillip, Minería y sociedad en el centro minero de Santa Eulalia, Chibuabua, Fondo de Cultura Económica, México, 1979; Mentz, Brígida Von, Sultepec en el siglo XIX. Apuntes históricos sobre la sociedad de un distrito minero, El Colegio Mexiquense / Universidad Iberoamericana, México, 1989; Pérez Rosales, Laura, Minería y sociedad en Taxco durante el siglo XVIII, Universidad Iberoamericana, México, 1996; Villalba Bustamante, Margarita, Economía y sociedad de un pueblo minero, Universidad Nacional Autónoma de México, Tesis de maestría en historia, México, 1999.

5 Velasco Ávila afirma que "la más espectacular de todas las explotaciones mineras coloniales" fue la Valenciana gracias a sus ininterrumpidas utilidades anuales de 600 mil y un millón 200 mil pesos entre 1766 y 1810. Brading,
} 
No obstante, el aumento de la producción de Guanajuato y de la Valenciana se vio ensombrecido por los conflictos mineros que suscitaron dos tipos de actos. Por un lado, el denuncio de nuevas pertenencias, la perforación de tiros y, la expansión de las obras subterráneas propias de la infraestructura de esta mina, que afectaron las minas colindantes. $\mathrm{Y}$, por el otro, los denuncios de minas abandonadas y terrenos vírgenes del subsuelo, de los empresarios mineros que poseían aquellas colindantes. De lo anterior se deduce que el crecimiento de las grandes empresas se logró en medio de conflictos entre mineros de distintos grupos económicos y sociopolíticos. Para comprender esto cabe considerar el papel protagónico que jugaron los propietarios de la Valenciana, lo que ocurrió gracias a tres factores: el capital que acumularon; la adquisición simultánea de múltiples bienes, como haciendas de beneficio y haciendas agrícolas; y la ocupación de cargos políticos, a través de los cuales se tuvo acceso vitalicio al poder local. Pero todo ello ocurrió junto a la existencia y actividad de numerosos medianos y pequeños mineros, que participaron en la producción general de metales de Guanajuato y Nueva España ${ }^{6}$.

Las minas, que además de la Valenciana, contribuyeron al aumento de la producción de metales de Guanajuato fueron Rayas, Sirena, Villalpando y el Cubo. Entre las menos conocidas hasta ahora se encontraban las minas Nuestra Señora de Guadalupe de Tepeyac (Tepeyac), Señor de San José de Quebradilla (Quebradilla), Señor San José de no Pensada (No pensada), Encarnación del Divino Verbo (Encarnación) y la Liberal mano de Dios (la Liberal). Los propietarios de todas ellas intentaron resistir principalmente el decisivo avance expansivo de Valenciana y Tepeyac en el tramo de la veta madre que se estudia aquí. Claro que éstos no fueron los únicos procesos judiciales vinculados a conflictos mineros, provocados por la pretensión de los empresarios de obtener la concesión de terrenos aledaños a las suyas.

Para explicar esa resistencia, sin conocer la proporción con que cada una participó en la producción global de metales del distrito -la cual, de conocerse, permitiría estimar el valor del interés económico representado en juicio-, he considerado otros dos factores. El primero, el número de pertenencias que comprendían las minas antes y después de las disputas; el segundo, la trayectoria de los concesionarios que las poseían, reconstruida a partir de la adquisición de otras minas y de haciendas de beneficio, y de su inserción o no en las instituciones político administrativas locales y virreinales. El objetivo es visualizar de qué manera ambos factores pudieron influir en la resolución de los conflictos mineros. Para ello

D., Mineros y comerciantes, Op. Cit., p. 349 y 378; Velasco Ávila, C., Estado y minería, Op. Cit., p. 218-220; Vilar, P., Oro y moneda, Op. Cit., p. 348.

${ }^{6}$ Hausberger, B., La Nueva España, Op. Cit., p. 71; Villalba Bustamante, Margarita, "El gran potencial de los pequeños y medianos mineros de Guanajuato en la segunda mitad del siglo XVIII", Nuevo Mundo Mundos Nuevos, n¹5, 2015, sección Coloquios, http://nuevomundo.revues.org/67764, consultado el 12 de marzo de 2017. 
se debe recordar que su participación en la producción mencionada no fue nada despreciable, aún cuando su actividad estuvo marcada por el amplio desequilibrio entre el número de minas descubiertas, las activas y las inactivas (parcial o totalmente) ${ }^{7}$. De ese desequilibrio dieron cuenta los oficiales de la Real Hacienda en 1774, al informar que, de 177 minas registradas, mucho más del $50 \%$ estaban inactivas ${ }^{8}$. De esto se podría deducir que la mayor parte de la veta madre de Guanajuato, su subsuelo y riqueza eran terreno disponible para nuevas explotaciones mineras. Sin embargo, los conflictos mineros que analizo revelan que eso era relativo, en la medida que una buena parte de las minas se habían comunicado entre sí. Asimismo, que las minas abandonadas eran muy codiciadas, tanto por los grandes empresarios como por los medianos y pequeños mineros, que veían en ellas la oportunidad de beneficiarse de la riqueza de la veta madre, precisamente en las inmediaciones de las minas más productivas.

\section{Conflictos mineros y justicia en Guanajuato, 1779-1812}

\subsection{Las disputas de los dueños de la mina de Tepeyac y sus vecinos}

Considerar la dimensión sociopolítica de los conflictos legales de propiedad minera permite visualizar la posición de los empresarios mineros en la industria local, regional y/o virreinal. Pero, sobre todo, comprender su interés por adquirir las pertenencias ${ }^{9}$ aledañas a sus minas, cuyo telón de fondo fue la expansión subterránea de éstas, así como lo que aquí llamo el acaparamiento del subsuelo, en Guanajuato, durante las últimas décadas del siglo XVIII y principios del XIX. En particular, a partir del aumento de la producción de metales preciosos, generado por la bonanza que experimentó la mina de la Valenciana desde 1770, así como la rehabilitación posterior de Rayas y otras minas en la década siguiente.

En este periodo, muy escasas minas sumaron tres pertenencias, y sus dueños no sólo se contaron entre los empresarios mineros más importantes del lugar, sino que entre ellos surgieron las más fuertes y largas disputas causadas por denuncios de nuevas pertenencias. Por lo tanto, supongo que sólo uno o dos empresarios con capital acumularon en sus minas

\footnotetext{
${ }^{7}$ López Miramontes, A. \& Urrutia Stebelski, C., Las minas de Nueva España, Op. Cit., p. 19.

8 Villalba Bustamante, M., "Economía y sociedad", Op. Cit., p. 74.

9 Una "pertenencia" era el terreno concesionado al poseedor de una mina para extraer metales del subsuelo. Al primer terreno podían agregarse otros colindantes, una vez que la superficie del primero estuviera totalmente en explotación y se necesitara extender los trabajos subterráneos. Así, la infraestructura de una mina pudo sumar varios terrenos, cuya concesión causó conflictos cuando una o más minas colindantes eran afectadas, porque se invadían sus terrenos y/u obras o, cuando el dueño de una de ellas pretendía tener mejor derecho al terreno, por ser su mina más antigua. Una pertenencia medía 120 varas al hilo de la veta y 60 al echado, antes de entrar en vigor las Ordenanzas de minería de 1783; pero después éstas la ampliaron a 200 varas al hilo y 200 al echado. Véase Título $8^{\circ}$ de las Ordenanzas de minería. González, M. del Refugio, Ordenanzas de la minería, Op. Cit., p. 231-252.
} 
mayor número de pertenencias. Asimismo, supongo que esta acumulación benefició a las minas cuya expansión estuvo directamente relacionada con la importancia de sus inversiones, obras y producción.

Sin embargo, la ausencia de fuentes en torno a estos tres factores, mina por mina, me obligó a observar más de cerca la trayectoria de los empresarios y sus empresas, a fin de reconstruir el marco de los juicios legales en los cuales ventilaron sus diferencias. Esta trayectoria la analizaré tanto en el ámbito económico como político, considerando que estos juicios son una expresión de la estructura socioeconómica del México virreinal, caracterizada por la confrontación entre los grandes empresarios así como entre estos y los medianos y pequeños empresarios y, entre estos últimos. Esta manera de considerar los expedientes judiciales coadyuva a explicar uno de los procesos más relevantes del aumento de la producción de metales: la expansión de las minas más ricas y productivas ligada al acaparamiento del subsuelo, la cual, sin duda, fue una prioridad de la corona española, en tanto que las grandes empresas mineras constituyeron una fuente importante de ingresos reales.

Así, el primer conflicto implicó la actuación de uno de los mineros medianos con mayor reconocimiento a nivel regional y virreinal, gracias a su actividad empresarial y política. Se trata de Francisco de Septién y Arce, quien, en 1791 se opuso al denuncio que hizo José Manuel Jaimes, pequeño rescatador de metales, de la mina nombrada La liberal. Septién y Arce, poseedor de la mina colindante de Tepeyac, afirmó que el terreno que se concesionaría a aquella mina pasaría sobre una parte de Tepeyac. Otras minas aledañas eran las de No Pensada y Remedios $^{10}$, pertenecientes a Marcos Gutiérrez y Francisco de Echeverría, respectivamente. Gutiérrez también se opuso, pero la Diputación de minería de Guanajuato, presidida por Domingo de Arive, después de valorar las pruebas proporcionadas por ambas partes, así como el dictamen pericial respectivo, otorgó la concesión de La liberal a José Manuel Jaimes. Llegar a esta resolución sólo tomó seis meses; sin embargo, el litigio se tornó más complejo debido a la persistente oposición, tanto de Septién como de Gutiérrez.

José Manuel Jaimes pretendía abrirse paso como minero en uno de los mejores puntos de la veta madre, es decir, a un lado de la mina Tepeyac y muy cerca de la de Valenciana. Quince años antes había comprado, en subasta pública, una pequeña hacienda de beneficio, y desde entonces se dedicaba al rescate de metales a pequeña escala. Hacia la década de 1780 su situación mejoró notablemente: así se deduce del poder general para gestionar sus asuntos que otorgó a José Manuel de Espinoza, José Ignacio Leal y Araujo y Antonio de la Plaza,

${ }^{10}$ En 1791, Francisco de Echeverría, como descendiente de su último poseedor, denunció esta mina, porque temía que alguien se adueñara de ella, debido a que permaneció inactiva cierto tiempo. Marcos Gutiérrez asistió a la posesión que los peritos José de Liceaga y Francisco Xavier de la Rosa otorgaron a Echeverría. Archivo Histórico de la Universidad de Guanajuato (AHUG), Fondo Agencia de minería AGE, AHUG-AGE, Caja 8, carpeta 1, expediente (E) 5, junio 6 de 1792 a octubre 2 de 1804, f. 128-258. 
vecinos de Real de Catorce, Guanajuato y México, respectivamente ${ }^{11}$. Leal y Araujo también era apoderado de otros mineros, como Antonio de Obregón y Alcocer, conde de Valenciana, y el propio Francisco de Septién y Arce. No obstante, no se sabe si Jaimes poseía otras minas y/o haciendas de beneficio. Por su parte, Marcos Gutiérrez se incorporó a la industria minera desde los años 1760, pero parece que actuó más como apoderado en los asuntos de otros mineros que como propietario ${ }^{12}$.

Así pues, Francisco de Septién y Arce era el empresario minero más importante y el más férreo opositor a la concesión de La Liberal. A fines de la década de 1770 era comerciante y aviador ${ }^{13}$ de pequeños mineros y comerciantes de las cuadrillas de las minas de Cata, Rayas y Valenciana, así como de la hacienda de San Clemente ${ }^{14}$. También financió y se convirtió en apoderado de medianos mineros, como Joaquín Manuel de Castañeda, Pedro de la Riva, Miguel Rangel, entre otros ${ }^{15}$. De manera paralela, gestionó préstamos para sí mismo, hipotecando los bienes de su esposa Juana María Iriarte, que antes de casarse con él había sido viuda heredera de Martín de Septién y Montero ${ }^{16}$. Su rol como aviador le abrió las puertas a la propiedad minera. Entre 1783 y 1790 adquirió alrededor de 88 acciones de las minas Nuestra Señora de Guanajuato, San Juan Nepomuceno, Nuestra Señora de la Aparecida, Santísima Trinidad, la Resurrección y Nuestra Señora de Guadalupe de Tepeyac ${ }^{17}$,

${ }^{11}$ Archivo Histórico de la Universidad de Guanajuato (AHUG), Protocolo de cabildo (PC), AHUG-PC, enero 3 de 1777, f. 4-11; AHUG-PC, enero 2 de 1784, fs. 6v; AHUG-PC, septiembre 4 de 1787, f. 252v; AHUG-PC, octubre 10 de 1793 , f. 574 v.

${ }^{12}$ Un ejemplo, fue la venta de la hacienda de beneficio de Santiago de Rocha, a favor del conde de Valenciana, hecha a nombre de José Pantaleón y otros, el 10 de marzo de 1792, f. 126v. AHUG-PC, 4 de julio de 1793, f. 282v.

13 El aviador financiaba a los empresarios mineros mediante préstamos de distintos tipos. La corona española consideró a los aviadores indispensables para "conservar y promover la minería", ya que gran número de mineros carecía de capital. Las Ordenanzas de minería de 1783 definieron las condiciones de los contratos de avío para evitar la usura y el fraude, que eran causa de frecuentes pleitos. González, M. del Refugio, Ordenanzas de la minería, Op. Cit., p. 348.

${ }^{14}$ AHUG-PC, agosto 18 de 1777, f. 461-65; AHUG-PC, abril 17 de 1779, f. 223-25v; AHUG-PC, abril 15 de 1782, f. 164-68; AHUG-PC, enero 25 de 1785, f. 12v-15.

${ }^{15}$ Miguel de Casamande designó a Septién y Arce, su apoderado, para administrar dos acciones que poseía en la mina Nuestra Señora de Guanajuato. Por otra parte, Castañeda, De la Riva y Rangel suscribieron cada uno contratos de depósito irregular, obligándose a pagar a Septién una cantidad global de 26 mil pesos, en marzo de 1778, f. 111v-114. AHUG-PC, 5 de febrero de 1785, f. 19v-21v; AHUG-PC, 4 de mayo de 1785, f. 206-208v; AHUG-PC, 8 de octubre de 1790, f. 471-75.

${ }^{16}$ Septién y Montero fue un comerciante próspero, pero también un aviador, cuyo patrimonio incluyó una cantidad nada despreciable de barras de oro y plata, producto del financiamiento que acordó a distintos rescatadores de metales, entre los cuales se encontraba Bernardo Fernández Riaño. Su sobrino, Francisco de Septién y Arce, fue administrador de una de sus tiendas. Brading, D., Mineros y comerciantes, Op. Cit., p. 359-365.

${ }^{17}$ En 1790, Septién y Arce compró ocho acciones en la mina de Tepeyac por menos de 200 pesos cada una, pues sus últimos poseedores carecían de capital para pagar los gastos de producción. Los peritos que inspeccionaron esta mina, a fin de fijar el valor de sus obras, sostuvieron que los metales que producía no eran "beneficiables ni de aprecio alguno por ser de pura borrasca". Se requerían distintas obras para comunicar la mina con los labrados del 
situadas en distintos reales de minas de Guanajuato, así como la de Señor San José de Gracia, en el Real de Charcas, San Luis Potosí. En casi todas fue parcionero, esto es, no único dueño; además, la mayoría las obtuvo vía donación, acto realizado por mineros que requerían financiamiento para sus minas ${ }^{18}$. Septién poseyó también haciendas de beneficio, haciendas agrícolas y otros bienes.

La formación de este patrimonio permitió a Francisco de Septién y Arce acceder al poder político local. Es decir, pudo obtener los cargos públicos de Regidor capitular, Alcalde ordinario de segundo voto, Teniente general de alcalde mayor, Diputado de comercio, Diputado de minería y consultor del Real Tribunal General de Minería. De ahí se deduce que la participación de Septién en los asuntos de la industria minera, así como en los del comercio, fue decisiva. En 1795, al presentar su renuncia al último cargo, el tribunal la rechazó considerando un informe de los sustitutos y electores de la Diputación de minería, los cuales no juzgaron conveniente que se separara del mismo, porque Septién destacaba por el "talento, honradez, actividad y celo con que ha desempeñado este y otros destinos". El Real Tribunal de Minería afirmó que Guanajuato era el centro minero "más opulento y principal del reyno", y necesitaba de "sujetos de la habilidad, carácter, e integridad del referido consultor [Septién y Arce] para el buen despacho de sus muchos asuntos"19. Así, mientras este último gozaba de poder y aceptación en el ámbito sociopolítico cuando se opuso al denuncio de la mina La liberal, sus contrapartes no sólo carecían de ese poder sino también padecieron el rigor de los empresarios mejor consolidados que se interesaron en sus minas. La estrecha relación entre los empresarios y la corona española -cuyo interés era promover la producción de

tiro, así como sacar los tepetates, que impedían la circulación del aire y, debido a que el tiro estaba parcialmente inundado y contaba sólo "dos gualdras y peones de malacate", urgía construir galeras y otras obras, cuyo valor total se estimó en más de 30 mil pesos. Asimismo, se hizo hincapié en que los últimos poseedores habían invertido más de 100.000 pesos, sin producirse la riqueza deseada, porque los metales de Tepeyac no eran "beneficiables", como sucedía "cada día en este mineral, aún en diversas minas con mucho mayor expendio de caudal". AHUG-PC, 24 de diciembre de 1782, f. 542v-546; AHUG-PM, 9 de enero de 1783, f. 198-200; AHUG-PM, 21 de junio de 1783, f. 282; AHUG-PM, 18 de noviembre de 1783, f. 334v-337v; AHUG-PM, 20 de julio de 1785, f. 144-145v; AHUGPM, 20 de febrero de 1787, f. 212-214v; AHUG-PM, 8 de marzo de 1790, f. 221-255.

${ }^{18}$ Francisco de Septién y Arce adquirió así nuevas obligaciones financieras. Un ejemplo: al aceptar las ocho acciones que le donaron en la mina Nuestra Señora de la Aparecida, se comprometió a invertir ocho mil pesos en su "excavación, cultivo y laborío". Sin duda, el conjunto de este tipo de obligación representó una inversión importante para Septién y Arce, lo cual reforzó su presencia como empresario minero y aviador, al mismo tiempo que como funcionario desplegaba una actividad decisiva en la Diputación de minería y otras instituciones. Todo esto lo hacía un "buen vasallo" ante los ojos del rey, en tanto que la vulnerabilidad de sus contrincantes se explica por lo contrario; es decir, por tratarse de mineros sin una larga ni sólida trayectoria que, habiendo adquirido pequeños fundos aledaños a minas de reconocida riqueza, aspiraban a gozar de ella. 18 de noviembre de 1783 , f. $334 \mathrm{v}$.

19 AHUG-PM, 20 de febrero de 1787, f. 212-214v; AHUG-PC, 27 de julio de 1791, f. 300-312v; Archivo Histórico del Palacio de Minería (AHPM), Libros manuscritos (M. L.) 150 B, 22 de agosto de 1795, f. 323-324; AHPM-M. L. 151B, 3 de septiembre de 1796, f. 358. 
metales, así como evitar que los conflictos mineros causaran más pérdidas administrando una justicia "breve y sumaria"- favoreció la pretensión de algunos grandes y medianos empresarios, de acaparar el subsuelo para asegurar la expansión de sus minas.

El contraste entre el perfil de Jaimes y su principal opositor tuvo su equivalente en la composición de sus minas. Esto es, las minas La liberal y Remedios contaban con una pertenencia cada una, mientras las No Pensada y Tepeyac avanzaban hacia su segunda y tercera pertenencia, respectivamente. La Liberal estaba en manos de un sólo poseedor en tanto que Tepeyac constituía una compañía minera con varios accionistas, representados por Septién y Arce. La Liberal era apenas una bocamina, a la que debía darse una profundidad de tres estados para formalizar la concesión a favor de Jaimes, en tanto que Tepeyac contaba ya con un tiro de 221 varas de profundidad, equivalentes a casi 185 metros, así como distintas obras subterráneas en las que se invirtieron 100.000 pesos o más ${ }^{20}$. De ahí que el valor de las minas en disputa, y el interés económico que cada una representaba para la corona española y su Real hacienda, en términos de impuestos al oro y la plata, eran potencialmente distintos. Sólo un año antes, peritos expertos sostuvieron que la mina Tepeyac estaba emborrascada y sus metales eran pobres, pero Septién y Arce afirmó que entonces producía ricos metales. Esto podía ser cierto si se considera que Septién y sus socios denunciaron, en 1791 y 1794, la segunda y tercera pertenencias de Tepeyac, indicando que sus obras subterráneas rebasaron los límites de su primer terreno, lo cual generó conflictos con otras minas colindantes, cuyos poseedores no sólo eran mineros de menor importancia, sino que también se disputaban entre ellos el derecho a explotar una parte del subsuelo. No obstante, es difícil pensar que en el lapso de sólo tres o cuatros años Francisco de Septién y Arce y sus socios hubieran sido capaces de construir obras que comprendieran el área de dos pertenencias o más. Pues, por un lado, en la década de 1780, Septién solicitó varios préstamos que evidencian su necesidad de capital, a pesar de que administraba la fortuna de su esposa. Por otro lado, la experiencia muestra que era más demoroso expandir las obras de una mina en una sola pertenencia. Así ocurrió con la Valenciana, donde se realizaron trabajos durante casi diez años antes de lograr la primera bonanza y expandir sus obras más allá de la primera pertenencia. Esto explica la resolución de la Diputación de Minería, que la dejará sin efecto; asimismo, que el Real Tribunal General de Minería diera largas al asunto para luego apoyar esta determinación.

Por último, en la dimensión sociopolítica del conflicto cabe considerar la relación entre las partes litigantes y la Diputación de minería. Los jueces y asesores de esta institución eran empresarios mineros, cuya trayectoria avalaba su conocimiento sobre las minas, así como su

${ }^{20}$ En 1790, el Real Tribunal General de Minería confirmó que la mina Tepeyac fue trabajada con "particular empeño, y esfuerzo, dando para su habilitación un costoso tiro, erogando y consumiendo en todo la gruesa cantidad de más de cien mil pesos, como es público y notorio". AHUG-AGE, caja 6, carpeta 6, E 4, 17901831, f. 10-10v. 
capacidad para actuar como jueces ${ }^{21}$. Sin embargo, los estrechos vínculos entre éstos y las partes litigantes comprometieron su función. Así, el problema mayúsculo para administrar justicia fue la jurisdicción privativa en manos de empresarios que estaban muy bien posicionados económica, social y políticamente, pues estos controlaron la diputación y otras instituciones locales, como el Ayuntamiento ${ }^{22}$. No hay duda que, dado el carácter prioritario que asignaban a sus propios compromisos empresariales, los mineros efectivamente usaron las leyes para favorecer sus intereses y los de sus socios y aliados 23 .

La concesión que el juez Domingo de Arive acordó a José Manuel Jaimes dio lugar a que Francisco de Septién y Arce lo recusara. Así, Vicente Manuel de Sardaneta y Legaspi24, marqués

${ }^{21}$ El carácter de la justicia en los asuntos de minería se justificó legalmente, considerando tres elementos: la experiencia que la corona española obtuvo en otras materias, que por su "importancia y naturaleza" dieron lugar a la creación de jurisdicciones privativas, ejercidas por individuos de la misma profesión; la experiencia de España, Grecia, Roma, Alemania, entre otros, donde las minas eran gobernadas "por hombres prácticos e inteligentes con una jurisdicción privativa"; y, finalmente, la petición de los mineros de la Nueva España de 1774, en la que además de exponer los problemas fundamentales de la industria minera, propusieron la erección de un "tribunal privativo" que se hiciera cargo de los asuntos contenciosos de minería, entre otras cosas. Los jueces debían tener una instrucción "práctica y experimental", que no podía adquirirse sino a lo largo del trabajo de muchos años consagrados especialmente a las minas. La institucionalización de los nuevos tribunales mineros se tradujo así en más privilegios para los empresarios, que fungieron como diputados, electores y sustitutos de la Diputación de minería, así como consultores del Real Tribunal General de Minería, pero también en nuevos conflictos, causados por la participación de los mineros más importantes en los juicios contenciosos relativos a la propiedad minera, entre otras cosas. Brading, David, Mineros y comerciantes, Op. Cit., p. 435-448; Gómez Mendoza, Oriel, "Las nociones normativas de justicia y gobierno en la minería mexicana del siglo XVIII al XIX", Revista de Historia, Universidad de Chile, junio 2011, n³4, p. 114; González, M. del Refugio, Ordenanzas de la minería, Op. Cit., p. 401-403 y 422-457; Venegas de la Torre, Agueda, "Los privilegios mineros novohispanos a partir de las Ordenanzas de minería de 1783: los usos de la justicia", Revista Historia y Justicia, Santiago de Chile, $\mathrm{n}^{\circ} 5,2015$, p. 81; Howe, Walter, The Mining guild of New Spain and its Tribunal general, 1770-1821, Harvard University Press, Cambridge, 1949, p. 62-66.

22 Los diputados de minería eran electos anualmente, en una reunión en la que participaban los mineros matriculados, aviadores, maquileros y beneficiadores de metales; debían haber sido o ser mineros "de los más prácticos e inteligentes". Los diputados se convertían además en apoderados de todos los mineros de su jurisdicción, "para promover sus intereses y pretensiones y para todo lo demás como está en costumbre". La elección debía ser aprobada por el Real Tribunal General de Minería y el Superior gobierno de la Nueva España. Así, los jueces de minas se distinguían por poseer algunas de las minas más productivas de su jurisdicción, además de estar revestidos de un poder reconocido por otras instancias que también administraban justicia. Véanse los títulos $1^{\circ}, 2^{\circ}$ y $3^{\circ}$ de las Ordenanzas de Minería de 1783. González, M. del Refugio, Ordenanzas de la minería, Op. Cit., p. 389 y 422; Staples, Anne, "Diputaciones territoriales de minería" en Cincuenta años de bistoria en México, El Colegio de México, México, 1991, p. 274.

${ }^{23}$ Brading, D., Mineros y comerciantes, Op. Cit., p. 444; Flores Clair, Eduardo y Velasco Ávila, Cuauhtémoc, "Minería y poder político en México 1770-1856", Revista Historias, Instituto Nacional de Antropología e Historia, México, n5, 1984, p. 33-51; Langue, F., Mines et terres, Op. Cit., p. 94.

${ }^{24}$ Vicente Manuel de Sardaneta y Legaspi era uno de los más importantes y grandes empresarios mineros, gracias a su mina de Rayas, la segunda más productiva del distrito. También poseía las minas de Asunción, Santa Úrsula, La Cruz, Encarnación, Sirena, San Juan Nepomuceno y San José Promontorio, entre otras. Sardaneta poseía las haciendas de beneficio San José de Burras y San Matías, así como distintas haciendas agrícolas; financió a mineros y 
de San Juan de Rayas, ocupó ese cargo y designó como conjuez a Francisco Azpilcueta, enfatizando que la mayoría de los electores de la diputación estaba "legítimamente impedidos y otros excusados" a causa de su relación con los litigantes. Vistos los autos, Sardaneta ordenó, como antes hizo Arive, que se diera posesión de la mina la Liberal a Jaimes. Sin embargo, Septién y Arce recurrió de nuevo a la recusación del Juez de minas, seguramente para alargar el juicio. La Diputación de minería rechazó esta recusación argumentando que aquél fue oído en primera y segunda instancia y no cabía más apelación conforme a las ordenanzas. También señaló que la institución era una mera ejecutora de una sentencia ya confirmada por el Juzgado de Alzadas, y por ese motivo el juez no podía ser recusado ${ }^{25}$. Más tarde, este mismo Juzgado integrado por el intendente Juan Antonio de Riaño y los electores de minería Juan Francisco de Villamor y Gervacio Antonio de Irizar- dejó sin efecto el decreto de Vicente de Sardaneta y Legaspi, y mandó reponer el procedimiento a partir de la fecha en que lo dictó ${ }^{26}$.

Lo anterior se comprende en el contexto de las relaciones empresariales y sociopolíticas creadas por Francisco de Septién y Arce en los años 1780, al tiempo que incrementó su patrimonio y administró el de su esposa ${ }^{27}$. Cabe insistir en que Septién se convirtió entonces en una autoridad pública con gran influencia tanto en los gremios de minería y de comercio locales como en el Real Tribunal General de Minería. En 1785, Septién y Arce realizó sus contratos de avío más importantes a favor de mineros; fue electo Diputado de minería, junto con Antonio de Obregón y Alcocer, conde de Valenciana, para el periodo de 1785 a 1787, durante el cual gestionó distintas "gracias y privilegios" para las minas del distrito. Asimismo, ocupó el cargo de elector de la diputación de comercio entre 1788 y 1789, ejercido conjuntamente con los electores Andrés Sagaz y Herrera, Juan Francisco de Villamor, Gervasio Antonio de Yrizar y Juan Vicente de Alamán, entre otros. El primero, era su socio en la mina Tepeyac; el segundo y el tercero, fueron los conjueces de Juan Antonio Riaño en el Juzgado de Alzadas que, un año después, revocó la sentencia favorable al contrincante de Septién y Arce; y, el último, fue apoderado de éste para gestionar algunos asuntos de minería. Domingo de Arive, el juez de

rescatadores de metales y practicó el comercio. Por otra parte, Sardaneta fue regidor capitular y alcalde provincial del Ayuntamiento, diputado de minería, alguacil mayor y notario del Santo Oficio de la Inquisición. Asimismo, obtuvo el título nobiliario de marqués de San Juan de Rayas en 1774, y el rey le acordó la cruz supernumeraria de la Real Orden de Carlos III en 1783. En 1790, Sardaneta cumplió 50 años de carrera empresarial, a lo largo de la cual superó dos periodos de inestabilidad económica y financiera, 3 de marzo de 1741, f.45v-48; AHUG-RM, caja 1, E 6, 11 de diciembre de 1762, 8 fs.; AHUG-PC, 29 de abril de 1777, f. 238-244; AHUG-PC, 25 de abril de 1782, f. 189-191v; AHUG-PM, 11 de diciembre de 1782, f. 179-181v.

${ }^{25}$ En efecto, el artículo 16 del Título $3^{\circ}$ y $4^{\circ}$ sobre el procedimiento de los juicios contenciosos prevenía que, si el Juzgado de Alzadas confirmaba una sentencia de la Diputación de Minería o el Real Tribunal General de Minería, no se debía admitir ningún otro recurso. González, M. del Refugio, Ordenanzas de la minería, Op. Cit., p. 433.

${ }^{26}$ Bernardo Riaño fue aviado de Martín de Septién y Montero, y Juan Antonio Riaño fue acusado de favorecer a los montañeses. Brading, D., Mineros y comerciantes, Op. Cit., p. 441.

${ }^{27}$ En 1781, Juana María de Iriarte dio poder general a Francisco de Septién para administrar los bienes que heredó como única y universal heredera de Martín de Septién y Montero. 
primera instancia que dictó la sentencia, estuvo ausente en la junta en la cual Septién fue designado elector de comercio $^{28}$.

Para 1790, Septién y Arce compró Tepeyac aprovechando la mala situación de esta empresa y sus dueños. Un año después de esa adquisición, ocupó de nuevo el cargo de Diputado de minería y se convirtió en consultor del Tribunal general de minería, institución a la que se opuso en los años subsecuentes en defensa de los intereses de la Diputación de minería de Guanajuato. La confrontación con Fausto de Elhuyar fue directa, pero esto no vulneró el incipiente poder de Septién y Arce ${ }^{29}$, pues logró prolongar indebidamente el proceso judicial con argumentaciones confusas, cuando la resolución de los jueces dependía esencialmente del peritaje que exigían las ordenanzas ${ }^{30}$. Sin duda, Septién y Arce y sus socios se preparaban para expandir su mina, lo que les permitiría disfrutar de riqueza similar a la de la mina colindante de Valenciana, y es probable que estuviesen confiados en poder impedir que los que fueren afectados tuvieran justicia 31.

Ahora bien, los aspectos técnicos de los juicios de propiedad minera eran esenciales para su resolución, pero no podré agotar aquí el análisis de sus implicaciones. Seis peritajes se realizaron a fin de determinar si la medida de la pertenencia de La Liberal perjudicaba o no a Tepeyac, y si se trataba de terreno virgen; pero los jueces desestimaron cinco de ellos donde se hizo constar que esa medida no afectaba a Tepeyac ${ }^{32}$. Septién y Arce se valió del único dictamen que le era

\footnotetext{
28 AHUG-PM, 24 de septiembre de 1785, f. 184-185; AHUG-PM, 21 de noviembre de 1785, f. 207-209v; AHUGPC, 23 de octubre de 1787, f. 299v-301; AHUG-PC, 11 de enero de 1788, f. 30v-36.

${ }^{29}$ Septién y Arce se involucró en conflictos políticos en el seno de la diputación, y en el Tribunal de Minería, que lo obligaron a crear alianzas para permanecer en el poder local y virreinal, así como a reforzar su presencia en otras instituciones reales. A esto sumó actos, como la donación que los montañeses de la Nueva España hicieron al rey de España, de más de 85.000 pesos, para la construcción de un navío. Entre los montañeses guanajuatenses se encontraban la condesa de Valenciana; Francisco de Septién y Arce; Manuel García de Cevallos; Manuel García Quintana; Pedro y Martín de la Riva; Manuel Cobo García y Andrés Sagaz y Herrera. Los últimos cuatro eran socios de Septién y Arce en la mina de Tepeyac. Brading, D., Mineros y comerciantes, Op. Cit., p. 443; Gazetas de México: compendio de noticias de Nueva España. Que comprenden los años de 1792 y 1793, dedicadas al Exmo. Señor D. Juan Vicente de Güemes [...] Por don Manuel Antonio Váldez, Tomo V, Imprenta de D. Felipe Zuñiga y Ontiveros, México, p. 23.

${ }^{30}$ La importancia de los peritos, así como de los reconocimientos, de las minas, era evidente. Las ordenanzas consagraron un título completo para determinar el perfil que aquéllos debían tener, así como ciertas normas sobre la forma de proceder para medir minas. Cabe destacar dos puntos: primero, que los peritos debían estar instruidos en diversas áreas de matemáticas y geometría subterránea, y acreditar el examen del Real Tribunal de Minería. Segundo, que los peritos debían ser españoles, criollos o "indios nobles de conocida patria, nacimiento y educación". Esto reforzó la presencia de una cierta élite de expertos, que se vincularon con los mineros más importantes del distrito, a cuyos intereses sirvieron. González, Ma. del Refugio, Ordenanzas de la minería, Op. Cit., p. 371.

${ }^{31}$ Brading, D., Mineros y comerciantes, Op. Cit., p. 447.

${ }^{32}$ Estos peritajes fueron practicados por Cristóbal de Ureña, Francisco Xavier de la Rosa, Manuel Ignacio Zerrato, Manuel Sendejas Ferrer y Juan Blanes.
} 
favorable, el del perito José de Liceaga, parcialmente apoyado por el de Juan Bautista Blanes ${ }^{33}$, quien señaló que, practicada de cierta manera, esa medida dañaría a Tepeyac. Para evitarlo propuso una forma distinta de medición. Blanes era Director y maestro de la Academia de aritmética y álgebra, y perito facultativo de minería aprobado por el Real Tribunal General de Minería desde 1784, lo que garantizaba la autenticidad de su dictamen e incluso el de los peritajes precedentes, realizados también por peritos acreditados con experiencia en la medición de minas conforme a las Ordenanzas de Minería de 1783.

A pesar de las pruebas técnicas favorables a la entrega de La Liberal a José Manuel Jaimes, el Tribunal General de Minería confirmó, en 1794, el decreto que dio por recusado a Vicente de Sardaneta y Legaspi, y mandó reponer el proceso. Después de la apelación de Jaimes y ciertas suplicaciones de Septién y Arce, ambos suspendieron sus gestiones en juicio. Así, nueve años más tarde, habiendo fallecido este último, el Juzgado de Alzadas mandó que su esposa e hijos nombraran un apoderado. Pero la primera renunció a su derecho, y el curador de los segundos, junto con los demás parcioneros de Tepeyac, solicitó declarar desierto el juicio a causa de su prolongada inactividad. No obstante, a inicios de 1804, el juzgado confirmó el decreto de 1791 que daba por recusados a Sardaneta y Legaspi. El juicio regresaba al mismo punto en el que estaba más de una década antes.

No obstante, Francisco de Septién y Arce logró expandir la mina de Tepeyac, no sólo oponiéndose a los denuncios de otras pequeñas minas colindantes, sino también al obtener de la Diputación de minería la concesión de su segunda y tercera pertenencias, las cuales denunció en 1791 y 1794, respectivamente. Esto generó conflictos paralelos que, sin minar su ánimo de posicionarse entre los mineros más importantes de Guanajuato, siguieron un proceso judicial similar al de La Liberal. Los descendientes de Septién y Arce y sus socios conservaron la extensión del subsuelo correspondiente a sus tres pertenencias, pero tuvieron que defenderlas de los avances expansivos de los dueños de la mina Valenciana, la gigante "dragaminas" más rica y productiva de las últimas décadas del siglo XVIII y principios del siglo XIX, tal como se verá.

\footnotetext{
33 Escamilla, Omar \& Ruth López, "Nociones generales de la teoría y práctica de la geometría subterránea. Escrita para la enseñanza de los alumnos del Real Seminario de Minería de México", Boletín de monumentos históricos, $\mathrm{n}^{\circ} 27$, 2013, p. 29-39; Urquiola, Ignacio, "El arte de medir y pesar aguas", Ciencia, Universidad Autónoma de Querétaro, $\mathrm{n}^{\circ}$ 2, vol. 1, p. 53-71, 2009; Villalba, M., "El trabajo en las minas de Guanajuato durante la segunda mitad del siglo XVIII", Estudios de Historia Novohispana, México, n48, 2013, p. 35.
} 


\subsection{Oposición contra los acaparadores de la mina Valenciana, 1800-1815}

La riqueza de la veta madre de Guanajuato, en el tramo donde se ubicaba la mina Valenciana, fue conocida en el mundo ${ }^{34}$, pero, sobre todo, en ese distrito donde los empresarios mineros fueron testigos de su prosperidad. Esta despertó interés en distintas minas abandonadas y terrenos vírgenes aledaños, que sin duda representaban una buena oportunidad de disfrutar parte de esa riqueza. En 1760, los parcioneros de Valenciana Antonio de Obregón y Alcocer, Pedro Luciano de Otero y Juan Antonio de Santa Anaobtuvieron la concesión de su primera pertenencia. Durante los primeros diez años de trabajo explotaron sistemáticamente su mina antes de lograr la gran bonanza que los convirtió, en 1770, en los empresarios más ricos y productivos de Guanajuato y de toda Nueva España. El aumento progresivo de su producción se tradujo en un doble proceso: la compra de medianas y pequeñas minas colindantes, cuya principal consecuencia fue la desaparición de éstas como unidades mineras, dada su anexión al subsuelo dado en concesión a Valenciana. No hubo conflictos entre los dueños de ésta y algunos de sus vecinos, a pesar de los denuncios de ciertas minas abandonadas o terrenos vírgenes aledaños, como La Liberal, o los terrenos denunciados por Francisco de Septién y Arce para su mina Tepeyac, sin que los de Valenciana se opusieran, porque no se perjudicaba su mina.

No obstante, desde 1789 y hasta poco después de la primera década del siglo XIX, los dueños de Valenciana enfrentaron una fuerte oposición de mineros que, sin poseer la misma fortuna, resistieron el avance expansivo de su empresa. Este fue visto como una amenaza por los medianos y pequeños mineros que poseían minas colindantes, quienes estaban indudablemente interesados en su expansión. Aunque los dos primeros conflictos no surgieron por el denuncio de minas o terrenos colindantes, sino por la comunicación reiterada de las obras subterráneas de las minas de Valenciana y San José de Quebradilla, cabe señalar que este tipo de comunicación se dio con cierta frecuencia entre otras minas. En 1789 , los concesionarios de una y otra empresa se conformaron con la determinación de la Diputación de minería, en el sentido de que el terreno donde ambas se comunicaron correspondía a la primera, dada su mayor antigüedad. No obstante, el dueño de Quebradilla, Domingo de la Presa, denunció más tarde varios huecos existentes entre su mina y las de Valenciana y Tepeyac, originando así un largo juicio, que nunca fue resuelto. Este caso mostró de nueva cuenta el peso de la desigual posición económica y sociopolítica de las partes en disputa, pues, mientras los dueños de Valenciana expandieron su empresa en más

\footnotetext{
${ }^{34}$ Cabe recordar que Alejandro von Humboldt comparó las características de la mina Valenciana con una de las minas más ricas de Europa, Himmelsfürt, en Sajonia; asimismo, mostró que la primera producía anualmente 360 mil marcos de plata, mientras la segunda producía sólo 10 mil. De esta manera destacó la gran proporción con la que Guanajuato participaba en la producción mundial de plata, lo que ha sido objeto de numerosos estudios historiográficos. Brading, D., Mineros y comerciantes, Op. Cit., p. 379; Humboldt, A., Ensayo político, Op. Cit, p. 524; Villalba Bustamante, M., "Economía y sociedad", Op. Cit., p. 115.
} 
de doce pertenencias en los años siguientes, los de Quebradilla y Tepeyac sólo obtuvieron la concesión de dos y tres pertenencias, respectivamente. Esto se debió, en gran parte, a cuatro factores: la creciente producción de metales de Valenciana; las fuertes reinversiones en sus obras subterráneas; la introducción de ciertas innovaciones técnicas; y la liquidez de sus socios. Y ello, sin contar que sus relaciones sociopolíticas fueron igualmente determinantes en su consolidación, debido a su inserción en las instituciones públicas locales y virreinales, así como a los méritos que les reconoció la corona española, lo que, por ejemplo, para Antonio de Obregón significó obtener el título de conde de Valenciana en 1780.

El denuncio de la segunda pertenencia de la mina Valenciana -hecho en 1800 por María Guadalupe de Barreta y Torrescano, condesa de Valenciana, y sus socios-, podía afectar las minas colindantes de San José de la Gavilla, Encarnación del Divino Verbo (Encarnación), San José de Esperanza (Esperanza) y San Francisco de Paula de los Alisos (Alisos) ${ }^{35}$. Se trataba de cuatro medianas y pequeñas compañías mineras constituidas cada una por más de dos socios, cuyas trayectorias diferían enormemente. Por ejemplo, los concesionarios de la mina de Encarnación eran José Máximo Ruiz Castañeda, Josefa Antonia García, Vicente Manuel de Sardaneta y Legaspi, Domingo de Rábago, Matías del Rivero y José Manuel Santa Ana $^{36}$. Sardaneta y Legaspi poseía tres acciones en dicha mina, pero era mejor conocido por la riqueza de su mina de Rayas, la segunda más productiva de Guanajuato, en tanto que Matías Rivero y José Manuel Santa Ana no destacaban como empresarios mineros. Esta asociación entre distintos tipos de empresarios revela la conjunción de intereses representados por una sola empresa involucrada en el conflicto, así como la complejidad de los juicios contenciosos relativos a la posesión del subsuelo.

La diputación de minería citó a los dueños de las cuatro minas antes mencionadas y designó al perito Ramón Cobo para inspeccionar la mina Valenciana. José Máximo Ruiz Castañeda ${ }^{37}$, en su calidad de parcionero de las minas de Encarnación, Esperanza y Alisos, se opuso al denuncio mencionado por ser fraudulento, ya que los parcioneros de Valenciana se introdujeron furtivamente en la segunda pertenencia de Encarnación. Por este motivo, pidió que se les condenara a perder el cañón que excavaron, así como a pagar el doble del valor de los metales que extrajeron ${ }^{38}$. Ruiz Castañeda afirmó además que

\footnotetext{
35 AHUG-AGE, caja 10, carpeta 4, E 3, junio 11-diciembre 25 de 1800, 57 f.

36 AHUG-AGE, c. 10, c. 4, E 3, f. 22.

${ }^{37}$ José Máximo Ruiz de Castañeda, vecino de México y capitán del regimiento de la provincia de Tlaxcala, era hijo de Pedro Ruiz de Castañeda, el cual avió la mina de Rayas a fines del siglo XVII y principios del XVIII. En 1762, Vicente de Sardaneta y Legaspi se obligó a pagar al primero más de 48 mil pesos, vinculados a un adeudo mayor de avíos proporcionados a su padre, 23 de febrero de 1762, f. 85; AHUG-PC, julio 16 de 1783, f. 232.

38 Véase el título $8^{\circ}$ de las Ordenanzas de Minería de 1783. González, M. del Refugio, Ordenanzas de la minería, Op. Cit., p. 242.
} 


\title{
Revista Historia y Justicia
}

\begin{abstract}
"los dueños de Valenciana estarán colmados de satisfacción al ver este pobre pedimento con el hecho público de que en diecisiete años que hace que rigen nuestras nuevas ordenanzas, se han tragado por debajo de la tierra, y con veta en mano, cuatro minas, que son San Ramón; el terreno en que se ubicaba la Milanesa, el Santo Cristo de Burgos y la Gavilla, sin que ninguno de sus dueños se hubiera preguntado ¿con qué título o autoridad han traspasado todas las cuadras correspondientes a su echado sin denunciar tamaño terreno? Pero yo que me hallo invadido del mismo modo he de hacerles ver que habiendo tirado al viento opuesto contra Quebradilla y Tepeyac, once pertenencias, no pueden tirar mayor número contra Encarnación" 39 .
\end{abstract}

A la Junta de avenencia, presidida por el diputado de minería Martín de la Riva, asistieron Ruiz Castañeda; los apoderados de María Guadalupe Barrera de Torrescano y de los hijos de Pedro Luciano de Otero, representando los intereses de los parcioneros de la Valenciana; y, por último, José María e Ignacio Fuentes Laso de la Vega, dueños de la mina de Esperanza. Estuvieron ausentes Ramón de Liceaga y Francisco de Villamor, socios de la mina de Gavilla. Con esta junta se trataba de evitar un largo y costoso juicio que afectaría al Real erario y público en general; sin embargo, después de una reñida discusión no se llegó a ningún acuerdo. Este fracaso se debió sin duda a la multiplicidad de intereses que representaban los más de quince mineros involucrados en el conflicto. No obstante, destacó la oposición de José Ruiz Castañeda, pues era parcionero de las minas de Encarnación y Esperanza y dueño único de Alisos. Además, contó entre sus socios a Domingo de Rábago, conde de Rábago, almacenero de México y aviador de distintos mineros guanajuatenses, así como Vicente Manuel de Sardaneta, con quien tuvo negocios en las décadas precedentes debido a ciertos avíos que concedió a la mina de Rayas.

Los dueños de Valenciana argumentaron, por un lado, que esta mina salió de sus pertenencias y el terreno denunciado era virgen y, por el otro, que los socios de la mina Encarnación no acreditaron la legitimidad de su interés por no haber presentado sus títulos de propiedad. Asimismo, faltaba comprobar, mediante la medición hecha por perito, si las obras de la mina Valenciana habían salido de sus pertenencias.

A mediados de 1800, el perito Ramón Cobo, acompañado del diputado Martín de la Riva, midió desde el centro del tiro de Nuestra Señora de Guadalupe de la mina la Valenciana, al hilo de la veta norte, 45 grados al oeste, poco más de 240 varas hasta la frente de Nuestra Señora de la Soledad, distancia que luego recorrieron por el exterior hasta llegar al "cerro del tiro nuevo, entre los dos caminos que van para Santa Ana"40. Aunque se mostró que el terreno de que se trataba efectivamente era virgen, se requería hacer una inspección similar en la mina Encarnación, por el rumbo que Ruiz Castañeda y sus socios sostuvieron que se les

${ }^{39}$ AHUG-AGE, caja 10, carpeta 4, E 3, 1800, f. 8.

40 AHUG-AGE, c. 10, c. 4, E 3, f. 2v. 
ocasionaba perjuicio. Pero estos se enfrascaron en el tema de la legitimidad de la posesión de Encarnación, alegando que los títulos de su mina se encontraban depositados en otro tribunal, sin aportar prueba de ello. Esto introdujo una serie de argumentaciones y contraargumentaciones inútiles en el debate judicial.

En 1769, Encarnación fue registrada por el cura José Francisco Barbosa y Jordanes; pero éste, ocho años después, donó seis de sus veinticuatro acciones a Vicente Manuel de Sardaneta y Legaspi, a cambio de que éste invirtiera ocho mil pesos en ella. A principios de la década de 1780, Barbosa cedió seis acciones a Domingo de Rábago ${ }^{41}$, una de ellas vía compraventa por un precio de 1.250 pesos. De lo anterior se deduce que el valor de dicha mina era aproximadamente 30 mil pesos. En tanto, de su ubicación estratégica-cerca de las de San José de la Gavilla, Esperanza y Valenciana-, así como del interés expreso de los concesionarios involucrados en el conflicto, se infiere un promisorio potencial mineralógico y productivo. No obstante, más tarde, Barbosa Jorganes y Sardaneta Legaspi vendieron seis de sus acciones a Domingo de Rábago, a fin de que éste invirtiera en la prosecución del tiro de su mina ${ }^{42}$. De ahí que Domingo de Rábago acumuló doce de la mina Encarnación, José Francisco Barbosa y Jorganes conservó ocho, Vicente Manuel de Sardaneta y Legaspi conservó tres, y Matías del Rivero Valdez y Josefa Antonia García solo una, que luego donaron a José Manuel de Santa Ana. La falta de capital de Barbosa y Sardaneta favoreció que el conde de Rábago se convirtiera en socio mayoritario de la empresa, en el curso de poco menos de un año y medio. Esto prueba el interés representado por la mina de Encarnación, cuyos dueños se opusieron al denuncio de los dueños de Valenciana.

Este pleito era entre nobles -el marqués de Rayas y el conde de Rábago contra el conde de Valenciana y sus socios, los condes de Pérez Gálvez y de la Casa Rul-, pero también entre los medianos y pequeños mineros asociados con unos y otros. El trasfondo social del conflicto permite comprender el alcance de los vínculos existentes entre las partes, así como entre éstas y las autoridades; y también permite saber de qué manera esto determinó su resolución.

\footnotetext{
${ }^{41}$ Domingo de Rábago era miembro de una familia de la élite montañesa que llegó a Nueva España a ocupar cargos político-administrativos. Fue miembro del Consulado de Cádiz, y al llegar a la Ciudad de México ocupó el cargo de familiar del Santo Oficio. También se convirtió en un comerciante con negocios importantes en Guanajuato, donde otros miembros de la familia mantuvieron relaciones comerciales con mineros y comerciantes del lugar. Un ejemplo es Juan Manuel Gutiérrez de la Concha, socio de una compañía comercial con Francisco Antonio de Rábago, cónsul del Consulado de comerciantes de México, comisario real de Guerra y Marina y familiar del Santo Oficio. Pérez Vejo, Tomás, "La vida como estereotipo: memorias de un comerciante montañés en la Nueva España", Historia Mexicana, vol. LVII, n¹, México, 2007, p. 197; AHUG-PC, 7 de enero de 1768, f. 167-169.

42 AHUG-AGE, caja 13, carpeta 1, E 4, f. 24-25; AHUG-PC, 29 de abril de 1777, f. 238-244; AHUG-PC, 16 de junio de 1777, f. 368; AHUG-PC, 18 de julio de 1781, f. 221; AHUG-PC, 6 de agosto de 1781, f. 251; AHUG-PC, 25 de abril de 1782, f. 189-191v; AHUG-PC, 1 de febrero de 1783, f. 58-61v.
} 
Otro elemento decisivo fue la estructura de las minas de Encarnación, Esperanza y Alisos, constituidas por una sola pertenencia, mientras que Valenciana tenía once hacia el sur de la veta, y sus dueños pretendían la segunda al noroeste. Esto complejizó el debate judicial dada la múltiple participación de empresas y empresarios, cuyos intereses se vieron afectados simultáneamente por la expansión de una o más minas. Por ejemplo, en 1790, los dueños de la mina de Encarnación solicitaron la ampliación de su pertenencia hasta que alcanzara 200 varas, de acuerdo con las ordenanzas, lo que consintieron los dueños de Valenciana, en tanto que los de la Esperanza se opusieron ${ }^{43}$. Ese año, el asesor de la Diputación de minería recomendó dar curso a la oposición de los concesionarios de Esperanza, y asimismo, a otro juicio que enfrentaba a las minas de Nuestra Señora de Guanajuato, Encarnación y Esperanza, causado por el denuncio de pertenencia hecho por los dueños de esta última. Cada juicio seguía entonces un proceso diferenciado, que impedía a los jueces agilizar el actual conflicto entre la mina de Valenciana y varias de sus colindantes. Y, aunque no se sabe cómo se resolvieron los tres juicios, es claro que los concesionarios de las minas involucradas en el litigio de 1800 se disputaron entre sí, diez años antes, los terrenos del subsuelo inmediato a aquellas. No había duda pues sobre el potencial mineralógico y productivo del tramo de la veta madre, donde se localizaban las minas antes mencionadas $y$, menos aún que sus dueños tenían un objetivo común: beneficiarse del gran aumento de la producción de metales preciosos en Guanajuato.

Los juicios descritos permiten observar cómo los intereses empresariales influyeron en el papel que jugaron los Jueces de minas. Transparentan también la ineficacia de la justicia privativa en los asuntos de minería. Al mismo tiempo, muestran la faceta políticoadministrativa de los conflictos mineros, los cuales se caracterizaron por las frecuentes recusaciones de los jueces y sus asesores, así como por las excusas de éstos cuando eran designados. Por ejemplo, en el juicio sobre la ampliación de Encarnación, de 1790, la diputación se halló impedida para actuar porque Miguel Fernández Riaño se excusó de conocer el denuncio de nueva pertenencia de la mina de Esperanza, al igual que los sustitutos y electores de minería, argumentando "estar impedidos legalmente para actuar como jueces".

Los desacuerdos entre el Juez de minas y sus asesores fue otra constante en los conflictos mineros. El Licenciado Ramón Francisco Carrasco, abogado de la Real Audiencia de México, señaló que de la providencia que se emitiera sobre la medida solicitada por los parcioneros de Encarnación en el primer juicio, dependía la resolución del segundo. El juez Domingo de Arive no estuvo de acuerdo con este dictamen, por ello envió los autos al Licenciado Francisco Moreno Flores, quien recomendó ejecutar la medida mencionada por Carrasco, citando también al dueño de Esperanza. En la mensura participaron Domingo Arive, el perito titulado Francisco Ignacio de la Presa, así como José María de Oñate y Zepeda y José Antonio González, apoderados de los parcioneros de Encarnación y Esperanza,

${ }^{43}$ AHUG-AGE, caja 13, carpeta 1, E 4, f. 25-25v. 
respectivamente. Al medir 200 varas desde el centro de Encarnación, al hilo de la veta, rumbo norte, se comprobó que éstas llegaban hasta el muro de la galera del tiro de Esperanza, lo que causó la oposición de los concesionarios de esta última. Así, los juicios se eternizaron años sin importar, insisto, el carácter breve y sumario de la administración de justicia previsto por los artículos $5^{\circ}$ y $6^{\circ}$ del título tercero de las Ordenanzas, ni la obligación que imponía el artículo 7o de evitar que se hicieran "apelaciones maliciosas con el sólo fin de dilatar los juicios" 44 .

Asimismo, los conflictos referidos revelan que una estrategia extendida entre los concesionarios de minas era la invasión furtiva de minas colindantes a las suyas. José Ruiz de Castañeda argumentó que los dueños de Valenciana no sólo no denunciaron el primer terreno que excavaban por el lado donde se introdujeron furtivamente en la segunda pertenencia de Encarnación, sino también que la pertenencia en disputa la obtuvo en otro juicio contradictorio ese mismo año. Por ello, pidió a la diputación declarar improcedente la petición de aquéllos, además de condenarlos al pago doble del valor de los metales extraídos ${ }^{45}$. Ruiz Castañeda alegó asimismo que las declaraciones falsas de Jaime Hosta perito facultativo de minas, administrador y apoderado de Valenciana-, eran una expresión del "despotismo que engendró la riqueza de millones en los dueños de Valenciana, que tratan y miran con un soberano desprecio a los vecinos pobres de las minas colindantes". Mientras, estos últimos esperaban gozar igual fortuna defendiendo sus pertenencias, como él hacía con "la cuadra de una mina pobre como Encarnación", después de haberla trabajado 31 años y erogado en ella más de 200.000 pesos para salir de la primera pertenencia. No obstante, todo indica que Encarnación no se expandió más allá de una segunda pertenencia; asimismo, que las minas de Encarnación, Alisos y Esperanza integraban un único cuerpo geológico-minero, de ahí que las dos primeras se mantuvieron unidas gracias a su excavación conjunta en alrededor de 800 varas o más, separadas de Esperanza, con la que más tarde se siguió un juicio de delimitación de pertenencias ${ }^{46}$.

Otras cuestiones en el conflicto remitieron una y otra vez a despejar toda duda sobre si el terreno denunciado por los dueños de Valenciana era virgen o no; si el denuncio de la segunda pertenencia de Encarnación se hizo primero; si la medición de esta le causaba perjuicio a aquella -el perito Ramón Cobo afirmó que sí-; y, si la posesión de ciertas pertenencias era ilegítima o no. Estas dudas podían despejarse con relativa facilidad a través de la medición hecha por peritos. No obstante, la multiplicidad de los intereses empresariales, así como la preeminencia de los grandes empresarios, favorecieron la expansión de la mina Valenciana en detrimento de la de Encarnación. Supongo que ésta

${ }_{44}$ González, M. del Refugio, Ordenanzas de la minería, Op., Cit., p. 425.

45 AHUG-AGE, c. 10, c. 4, E 3, f. 37-50v.

46 AHUG-PC, 22 de noviembre de 1825, f. 314v. 
terminó por anexarse a la primera, tal como sucedió con las minas afectadas por el denuncio de la treceava pertenencia de Valenciana, el cual causó una nueva confrontación entre los parcioneros de esta mina, los de Tepeyac y los de Señor San José de Quebradilla ${ }^{47}$. A fines de 1812, la Diputación de minería notificó dicho denuncio a Domingo de la Presa, parcionero principal de Quebradilla, quien consintió en la entrega de la pertenencia a Valenciana siempre que no se perjudicara la suya. Pero los parcioneros de Tepeyac Santiago de Septién y Cobo, José Cobo Lavín, Francisco de Septién y Arce y Andrés de Sagaz y Herrera-, así como el de la mina No Pensada, José Antonio Campos, declararon que de ser así sus derechos eran vulnerados ${ }^{48}$. Entonces surgió un nuevo pleito entre los dueños de las minas de Valenciana, Tepeyac y No Pensada.

Estas empresas comprendieron de nueva cuenta un conjunto de quince parcioneros, entre los cuales se encontraban tres nobles -el segundo conde de Valenciana, el conde de Pérez Gálvez y el conde de la Casa Rul- insertos en diversos sectores de la economía regional y virreinal. Tabién debe contarse un grupo de medianos y pequeños mineros, como Andrés Sagaz y Herrera, Antonio Aguirre Campos o Fernando Alfaro, parcioneros de las minas de Tepeyac, No Pensada y Quebradilla, respectivamente. La trayectoria de estos últimos es difícil de seguir dada la escasez de información. Como en el juicio anterior, los dueños de Valenciana pretendieron llegar a un acuerdo, pero después de "muchas sesiones y disputas", así como del "reconocimiento de las minas de Valenciana y Tepeyac", del cual resultó un plano del perito Manuel Sendejas Ferrer, la controversia no se resolvió. Los parcioneros de Tepeyac sostuvieron que esto se debió a la "malicia" del apoderado de Antonio de Obregón y Barrera, segundo conde de Valenciana. Por su parte, Francisco de Septién y Arce pidió a la diputación desechar el denuncio de los de Valenciana, por ser "perjudicial, malicioso e ilegítimo". Septién argumentó que estos últimos hicieron su denuncio sin haber obtenido la legítima posesión de sus décima, onceava y doceava pertenencias, a fin de "echarse sobre Tepeyac, disfrutar sus riquezas y dar pábulo a su insaciable codicia”. Asimismo, Septién enfatizó que aquellos pretendían impedirle que ahondara el tiro de Tepeyac y aprovechara los ricos frutos que producía su mina, contraviniendo las ordenanzas ${ }^{49}$. Y que había obtenido sentencia favorable en el conflicto concerniente a la onceava pertenencia de Valenciana, pero la apelación de sus parcioneros permanecía aún sin resolver, aun cuando el perito de minas comprobó que la décima pertenencia de la Valenciana estaba trabajada fuera de veta, y la diputación decretó que, sólo en caso de que sus parcioneros la trabajaran conforme a la Ordenanza, podían solicitar la undécima ${ }^{50}$.

47 AHUG-AGE, caja 13, carpeta 1, E 4, 3 de noviembre de 1812 - 20 de abril de 1815, 38 f.

48 AHUG-AGE, c. 13, c. 1, E 4, f. 3-4.

49 González, M. del Refugio, Ordenanzas de la minería, Op. Cit., p. 247.

50 AHUG-AGE, Caja 13, carpeta 1, E 4, 1812-1815, f. 13v-14. 
En la Junta de avenencia respectiva participaron los apoderados de los parcioneros de las minas de Valenciana, Tepeyac y No Pensada, así como el juez José María Hernández Chico, diputado menos antiguo de minería, quien los exhortó a llegar a un acuerdo "en obsequio de la paz y tranquilidad pública y privada"; pero aquellos se negaron a toda transacción ${ }^{51}$. Existían tres procesos sin resolver: uno, sobre el denuncio de la treceava pertenencia de Valenciana; dos, el de la apelación de los dueños de esta mina en contra de la sentencia de la Diputación de minería favorable a la de Tepeyac; y el tercero, relativo al reconocimiento de ciertos labrados de Tepeyac, para determinar si el agua de esta inundaba a la Valenciana. Así, los tres conflictos se superpusieron a causa de la apelación sin resolver que estaba en el Real Tribunal de Minería.

A la oposición de los parcioneros de Tepeyac se sumó la de los parcioneros de la No Pensada, quienes pidieron a la Diputación de minería que rechazara el denuncio de los de la Valenciana porque el terreno que pedían era el que estaban disputando a los de Tepeyac, en otro juicio que se encontraba pendiente de resolver en el Consejo de Indias ${ }^{52}$. Esto muestra el alcance del interés representado por los grandes empresarios capitalistas que poseían la Valenciana, pero también la fuerte resistencia de medianos y pequeños empresarios, que los enfrentaron en una lucha desigual por obtener la concesión del subsuelo inmediato a sus minas. Esto revela también la capacidad financiera de unos y otros para cubrir costosos juicios, con la esperanza de promover la expansión de sus empresas. No obstante, los primeros siempre encontraron la manera de darle la vuelta a las resoluciones que desfavorecían sus intereses. En este caso, la diputación resolvió no acumular el expediente del denuncio de la treceava pertenencia de Valenciana con el que estaba pendiente en el Consejo de Indias, cuyo origen había sido el denuncio de la tercera pertenencia de Tepeyac al que también se opuso Antonio Aguirre Campos ${ }^{53}$. La diputación determinó continuar el juicio a su cargo, tomando en cuenta la necesidad de indagar si el terreno denunciado era virgen o no, pero, sobre todo, "la congruente y oportuna consideración de que sería la cosa más dura sujetar a los de Valenciana", haciéndolos esperar la resolución del expediente de España.

Es decir, se repetía la misma historia. A pesar de no conocer qué sentencia se dictó, resulta claro que los dueños de Valenciana prosiguieron sus labores y mantuvieron su posición como grandes empresarios mineros capitalistas de Guanajuato y Nueva España. No obstante, cabe insistir en destacar el comportamiento de los medianos y pequeños empresarios, como Domingo de la Presa, Francisco de Septién y Arce y José Antonio Campos, principales parcioneros de Quebradilla, Tepeyac y No Pensada, los cuales conservaron sus minas durante mucho tiempo más. Los descendientes de los dos primeros las retuvieron hasta bien avanzado el siglo XIX. De esto se deducen dos puntos centrales en la dinámica generada por el aumento

51 AHUG-AGE, C. 13, c. 1, E 4, f. 16.

52 AHUG-AGE, C. 13 , c. 1, E 4, f. 22.

53 AHUG-AGE, C. 13, c. 1, E 4, f. 28-34. 
de la gran producción de metales preciosos en Guanajuato en la época de estudio: el primero de ellos confirma que el poder económico y sociopolítico de los grandes empresarios no sólo les permitió mantener el control directo de la industria minera, sino también influenciar las instituciones locales y virreinales encargadas de gobernar y administrar justicia en los reales de minas novohispanos como Guanajuato. El segundo tiene que ver con la existencia y consolidación de ese poder: éste se tradujo en un sometimiento parcial de los intereses de los medianos y pequeños mineros, pero no en su anulación total. Unos y otros se necesitaban.

\section{Conclusión}

La gran producción de metales preciosos de la veta madre de Guanajuato, en las últimas décadas del siglo XVIII y principios del XIX, favoreció la expansión de las grandes empresas mineras, las que acapararon mayor número de pertenencias o terrenos en el subsuelo. El ejemplo más claro de esto fue el de la mina Valenciana, que acumuló trece terrenos, seguido de una de sus minas colindantes más importantes, Tepeyac, la cual adquirió sólo tres. Este acaparamiento del subsuelo se tradujo, a la vez, en la acumulación de acciones en las distintas minas situadas a lo largo de la veta madre de Guanajuato y otros lugares. Esta característica, propia de la estructura económica y sociopolítica de industria minera, fue apuntalada por las Ordenanzas de Minería de 1783. Las normas sobre la posesión del subsuelo, los conflictos mineros y la justicia privativa en materia de minería fueron diseñadas para privilegiar el crecimiento de los mineros novohispanos más productivos, y, en consecuencia, el de los que pagarían la mayor proporción de los ingresos que engrosarían las arcas del Real erario. Sobre todo, las que se consagraron al gobierno y administración de las instituciones políticoadministrativas, que, como la Diputación de minería, el Juzgado de Alzadas y el Real Tribunal de minería, estaban constituidas por los empresarios mineros más "inteligentes y prácticos" del distrito, los cuales, apoyados por asesores, no pudieron administrar una justicia "breve" y "sumaria" en los conflictos mineros, a causa de los artificios de los empresarios para tergiversar las leyes. En este contexto se instaló el principio de inequidad, que rigió la industria minera local y virreinal, la cual se tradujo en la consolidación de los grandes empresarios, como Antonio de Obregón y Alcocer o Vicente de Sardaneta y Legaspi, en la medida en que promovieron la riqueza de sus minas. Junto a ellos, los medianos y pequeños mineros -cuyas finanzas les permitieron defender sus derechos en costosos juicios para conservar la posesión de sus minas y garantizar su expansión-, mostraron una voluntad de defender su derecho a competir por las ganancias, y una experiencia colectiva, que conviene recuperar en la historiografía mexicana. 


\section{Fuentes}

\section{Inéditas}

\section{Archivo Histórico de la Universidad de Guanajuato, Guanajuato, México}

\section{a) Fondo Agencia de Minería, AHUG-AG, cajas}

6, carpeta 6, exp. 4, Juicio sobre el denuncio de segunda pertenencia hecho por Francisco de Septién y Arce y sus socios para su mina Tepeyac, 1790-1831, $180 \mathrm{f}$.

8, carpeta 1, exp. 5, Juicio de Francisco Septién y Arce y sus parcioneros en la mina Tepeyac contra el denuncio de la mina la Liberal mano de Dios hecho por José Manuel Jaimes, 6 de junio de $1792-2$ de octubre de 1804, f. 128-258.

9, carpeta 2, exp. 31, Autos seguidos por los dueños de la mina de Tepeyac sobre tercera pertenencia y oposición de Marcos Gutiérrez, 18 de agosto de 1795, 9 f.

9, carpeta 4, exp. 6, Juicio por la tercera pertenencia solicitada por Francisco de Septién y Arce al que se opusieron Petra Muñoz y Manuel Domingo Chavero, parcioneros de la mina No Pensada, 16 de agosto de 1796 - 17 de mayo de 1797, 79 f.

10, carpeta 3, exp. 6, Orden de sacar testimonio triplicado de los autos del juicio entre las minas Tepeyac y No Pensada, 2 de enero - 30 de mayo de 1799, $10 \mathrm{f}$.

10, carpeta 4, exp. 3, Denuncio de segunda pertenencia para Valenciana que afecta las minas colindantes de Gavilla, Encarnación, Esperanza y Alisos, seguido de la oposición de José Ruiz de Castañeda, 11 de junio - 25 de diciembre de 1800, $57 \mathrm{f}$.

13, carpeta 1, exp. 4, Denuncio de la doceava pertenencia de la mina de Valenciana hecho por sus concesionarios y oposición de los dueños de Tepeyac y No Pensada, 3 de noviembre de 1812-abril 20 de 1815, 38 f.

\section{b) Protocolo de Cabildo, AHUG-PC}

Cesión de derechos de haciendas de minas de Matías del Rivero y Valdés a favor de Antonio de Obregón y Alcocer, 16 de julio de 1783, f. 232.

Compraventa de la hacienda de San Gabriel Barrera hecha por Francisco de Septién y Arce a favor de la condesa de Valenciana, 27 de julio de 1791, f. 300.

Compraventa la hacienda San Nicolás Obispo a favor de José Manuel Jaimes, 3 de enero de 1777, f. 4.

Compraventa seis barras de la mina Encarnación a favor de Domingo de Rábago, 25 de abril de 1782, f. 189.

Depósito irregular de Juan Domingo de Rábago a favor de Francisco de Septién y Arce y Vicente Alamán, 29 de noviembre de 1798 , f. $329 \mathrm{v}$.

Donación de cuatro barras de la mina Encarnación de José de Barbosa y Jorganes a favor de Vicente de Sardaneta y Legaspi, 29 de abril de 1777, f. 238.

Donación de dos barras de la mina Encarnación de José Barbosa y Jorganes a favor de Vicente de Sardaneta y Legaspi, 16 de junio de 1777, f. 368.

Donación de barras de la mina San Miguel la Gavilla que hacen Manuel de Liceaga y Busto y otros a favor de Antonio de Obregón, 23 de octubre de 1777, f. 555v.

Donación de barras de la mina San Juan Nepomuceno a favor de Francisco de Septién y Arce, 24 de diciembre de 1782, f. 542v.

Donación de una barra de la mina Encarnación de Matías del Rivero a favor de José Manuel de Santa Ana, 1 de febrero de 1783, f. 58.

Elección de diputados de comercio a favor de Francisco de Septién y Arce y otros, 11 de enero de 1788, f. 30v. 
Elección de diputados de comercio a favor de Francisco Antonio de Septién y Arce y otros, 13 de enero de 1788, f. 42v.

Licencia de Vicente Manuel de Sardaneta y Legaspi, Tomás de Liecaga y otros dueños de las minas La Asunción, La Cruz y Santa Ursula a favor de Francisco del Río, 27 de julio de 1776, f. 270v.

Nombramiento de teniente general de alcalde mayor de Guanajuato a favor de Francisco de Septién y Arce, 9 de julio de 1787, f. 222.

Obligación de pago de Felipe Soria a favor de Francisco Septién y Arce, abril 17 de 1779, f. 223.

Obligación de pago de Domingo Presa, 7 de diciembre de 1819, f. 186.

Obligación de pago de Vicente Manuel de Sardaneta y Legaspi a favor de José Ruiz de Castañeda y otros, 23 de febrero de 1762, f. 85.

Poder de José Manuel Jaimes a Juan Antonio de la Plaza, octubre 10 de 1793, f. 574v.

Poder general de José Manuel Jaimes a José Ignacio Leal y Araujo para atender sus asuntos legales, 4 de septiembre de 1787 , f. $252 \mathrm{v}-254$.

Poder que otorga Vicente Manuel de Sardaneta para que administren su mina de Rayas, 3 de marzo de 1741, f. 45v.

Poder acordado por José Manuel Jaimes a José Manuel de Espinoza, residente en el Real de minas de Catorce, jurisdicción de Sierra de Pinos, 2 de enero de 1784, f. 6v.

Poder especial de Miguel de Casanande a favor de Francisco de Septién y Arce para administrar la mina Nuestra Señora de Guanajuato, 20 de marzo de 1778, f. 111v.

Poder que otorga Domingo Presa para vender cuatro barras de la mina San José de Quebradilla, 20 de julio de 1815, f. 151v.

Poder para continuar juicio de límites de las minas Encarnación y Esperanza, 22 de noviembre de 1825, f. 314v.

Recibo de depósito irregular de Andrés Sagaz y Herrera y Francisco de Septién y Arce a favor de Micaela Damiana, 10 de junio de 1782, f. 297.

\section{c) Protocolo de Minas, AHUG-PM}

Cesión de la mina San Juan Nepomuceno hecha por Vicente de Sardaneta y Legaspi, 11 de diciembre de 1782, f. 179.

Compraventa de barras de la mina Nuestra Señora de Guadalupe de Tepeyac a favor de Francisco de Septién y Arce y Manuel García de Ceballos, ocho y cuatro barras respectivamente, 8 de marzo de 1790, f. 221.

Donación de doce barras de la mina Señor San José de Gracia a favor de Francisco de Septién, 20 de febrero de 1787, f. 212.

Donación de barras la mina Espíritu Santo y Ánimas hecha por Vicente de Sardaneta y Legaspi, 19 de agosto de 1761, f. 356v.

Donación de ocho barras de la mina San Nicolás a Vicente de Sradaneta y Legaspi, 1 de agosto de 1757, f. 53v.

Donación de dieciséis barras de la mina Santísima Trinidad a favor de Francisco de Septién, 21 de junio de 1783, f. 282.

Donación de ocho barras de la mina nuestra Señora de la Aparecida a favor de Francisco de Septién y Arce, 18 de noviembre de 1783, f. 334.

Poder especial de Francisco de Septién y Arce para tomar posesión de la mina Resurrección, 20 de julio de 1785, f. 144.

Poder otorgado por los diputados de minería Francisco de Septién y Arce y Antonio de Obregón y Alcocer, 24 de septiembre de 1785, f. 184.

Poder de la Diputación de minería de Guanajuato para pedir al Superior gobierno lo necesario para la conservación de la minería, 21 de noviembre de 1785, f. 207.

Venta de seis barras de la mina San Nicolás a favor de Vicente de Sardaneta y Legaspi, 7 de julio de 1757, f. 44. Venta de barras de la mina el Buen Suceso a favor de Vicente de Sardaneta y Legaspi, 18 de marzo de 1758, f. 89. 


\section{d) Ramo Minería, AHUG-RM}

Caja 1, exp. 6, Venta de barras de las minas Asunción, Santa Úrsula a favor de Vicente Manuel de Sardaneta y Legaspi, exp. 6, 11 de diciembre de 1762, $8 \mathrm{f}$.

\section{Archivo Histórico del Palacio de Minería, Ciudad de México, México}

\section{Libros manuscritos, AHPM-ML}

150-B, Carta del Tribunal general de minería a la Diputación de minería de Guanajuato sobre renuncia de Francisco de Septién y Arce, 1795, f. 323-324.

151-B, Carta a la diputación de minería sobre los autos seguidos sobre la tercera pertenencia solicitada por Francisco de Septién, 3 de septiembre de 1796, f. 358.

\section{Publicadas}

Gaz̧etas de México: compendio de noticias de Nueva España. Que comprenden los años de 1792 y 1793, dedicadas al Exmo. Señor D. Juan Vicente de Güemes [...] Por don Manuel Antonio Válder, Tomo V, Imprenta de D. Felipe Zuñiga y Ontiveros, México, 1792-1793.

Monroy, Pedro, Las minas de Guanajuato. Memoria histórico descriptiva de este distrito minero, Secretaría de Fomento, México, 1888.

Pastor Fuster, Justo, Biblioteca Valenciana, Tomo II, Imprenta de José Ximeno, Valencia, 1827.

Ramírez, Santiago, Noticia histórica de la riqueza minera de México y su actual estado de explotación, Secretaría de Fomento, México, 1884.

\section{Bibliografía}

Antúnez Echegaray, Francisco, Monografía histórica y minera sobre el distrito minero de Guanajuato, Consejo de Recursos No Renovables, México, 1964.

Alatriste, Oscar, Desarrollo de la industria y la comunidad minera de Hidalgo del Parral durante la segunda mitad del siglo XVIII (1765-1810), Universidad Nacional Autónoma de México, México, 1983.

Amado Gutiérrez, Carlos, "La propiedad minera", Revista del Instituto de Investigaciones FIGMMG, vol. 13, n²5, 2010, p. 42.

Bakewell, P. J., Minería y sociedad en el México colonial, Zacatecas (1546-1700), Fondo de Cultura Económica, México, 1984.

Bargalló, Modesto, La minería en la América Española durante la época colonial, Fondo de Cultura Económica, México, 1955.
Brading, David, Mineros y comerciantes en el México Borbónico (1763-1810), Fondo de Cultura Económica, México, 1985.

Escamilla, Omar \& López, Ruth, "Nociones generales de la teoría y práctica de la geometría subterránea. Escrita para la enseñanza de los alumnos del Real Seminario de minería de México", Boletin de monumentos históricos, n²7, 2013, p. 29-39.

Flores Clair, Eduardo \& Velasco Ávila, Cuauhtémoc, "Minería y poder político en México 1770-1856", Revista Historias, INAH, México, n 5 , 1984, p. 33-51.

García Marín, José, “Quiebras en la administración de justicia novohispana del siglo XVIII", Historia. Instituciones. Documentos, Universidad de Sevilla, 1998, p. 249-266, disponible en https:// dialnet.unirioja.es/servlet/articulo?codigo $=63412$ 9, consultado el 10 de marzo de 2017. 
Girón Zúñiga, Nicolás, "Los jueces y el poder en el Norte Chico. Una aproximación a la trama política y económica de una sociedad en formación (1725-1790)", Tesis de Magíster en Historia, Universidad de Chile, Santiago de Chile, 2015, inédita.

González, María del Refugio, Ordenanzas de la minería de la Nueva España, formadas y propuestas por su Real Tribunal, Universidad Nacional Autónoma de México, México, 1996.

Gómez Mendoza, Oriel, "Las nociones normativas de justicia y gobierno en la minería mexicana del siglo XVIII al XIX", Cuadernos de Historia, Universidad de Chile, n³4, 2011, p. 109-126, http://www.scielo.cl/scielo.php?script $=$ sci arttext \&pid $=$ S0719-12432011000100005, consultado el 10 de marzo de 2017.

Hadley, Phillip, Minería y sociedad en el centro minero de Santa Eulalia, Chibuahua, Fondo de Cultura Económica, México, 1979.

Hausberger, Bernd, La Nueva España y sus metales preciosos. La industria minera colonial a partir de los libros de cargo y data de 1761-1767, IberoamericanaVervert, Berlín, 1997.

Humboldt, Alejandro, Ensayo político sobre el reino de la Nueva España, Ed. Porrúa, México, 1991.

Langue, Frédérique, Mines, terres et société à Zacatecas (Mexique), de la fin du XVIIe siècle à l'Indépendance, Université de la Sorbonne, París, 1992.

López Miramontes, Álvaro \& Urrutia Stebelski, Cristina, Las minas de Nueva España en 1774, Secretaría de Educación Pública / INAH, México, 1980.

Mentz, Brígida von, Sultepec en el siglo XIX. Apuntes históricos sobre la sociedad de un distrito minero, El Colegio Mexiquense / Universidad Iberoamericana, México, 1989.

Pérez Rosales, Laura, Minería y sociedad en Taxco durante el siglo XVIII, Universidad Iberoamericana, México, 1996.
Pérez Vejo, Tomás, "La vida como estereotipo: memorias de un comerciante montañés en la Nueva España", Historia Mexicana, México, vol. LVII, n¹, 2007, p. 193-262.

Stapless, Anne, "Diputaciones territoriales de minería" en Cincuenta años de historia en México, El Colegio de México, México, 1991, p. 273-291.

Urquiola, Ignacio, "El arte de medir y pesar aguas", Ciencia, Universidad Autónoma de Querétaro, n², vol. 1, 2009, p. 53-71.

Velasco Ávila, Cuauhtémoc, Estado y Minería en México (1767-1910), Fondo de Cultura Económica / SEMIP, México, 1988.

Venegas de la Torre, Agueda, "Los privilegios mineros novohispanos a partir de las Ordenanzas de minería de 1783: los usos de la justicia”, Revista de Historia y Justicia, Santiago de Chile, n5, 2015, http///revista.historiayjusticia.org, consultado el 10 de marzo de 2017.

Vildósola Fuenzalida, Julio, El dominio minero y el sistema concesional en América Latina y el Caribe, Editorial Latina, Venezuela, 1999.

Vilar, Pierre, Oro y moneda en la bistoria (1450-1920), Ediciones Ariel, Barcelona, 1979.

Villalba Bustamante, Margarita, Economía y sociedad de un pueblo minero: La Valenciana, 1760-1810, Universidad Nacional Autónoma de México, Tesis de maestría en historia, México, 1999.

Villalba Bustamante, Margarita, "El trabajo en las minas de Guanajuato durante la segunda mitad del siglo XVIII", Estudios de Historia Novohispana, México, n48, 2013, p. 36-83.

Villalba Bustamante, Margarita, "El gran potencial de los pequeños y medianos mineros de Guanajuato en la segunda mitad del siglo XVIII", Nuevo Mundo Mundos Nuevos, n¹5, 2015, sección Coloquios, http://nuevomundo.revues.org/67764, consultado el 12 de marzo de 2017.

Walter Howe, The Mining guild of New Spain and its Tribunal general, 1770-1821, Harvard University Press, Cambridge, 1949. 